\title{
Neutrophil-to-lymphocyte ratio (NLR) and platelet-to-lymphocyte ratio (PLR) as independent predictors of outcome in infective endocarditis (IE)
}

Marwa Sayed Meshaal ${ }^{1 *}$ (D, Abdo Nagi ${ }^{1}$, Ahmed Eldamaty ${ }^{1}$, Wae'el Elnaggar ${ }^{1}$, Mervat Gaber ${ }^{2}$ and Hussien Rizk ${ }^{1}$

\begin{abstract}
Background: Early and accurate risk assessment is an important clinical demand in patients with infective endocarditis (IE). The neutrophil-to-lymphocyte ratio (NLR) and platelet-to-lymphocyte ratio (PLR) are independent predictors of prognosis in many infectious and cardiovascular diseases. Very limited studies have been conducted to evaluate the prognostic role of these markers in IE.

Results: We analyzed clinical, laboratory, and echocardiographic data and outcomes throughout the whole period of hospitalization for a total of 142 consecutive patients with definitive IE.

The overall in-hospital mortality was $21 \%$. Major complications defined as central nervous system embolization, fulminant sepsis, acute heart failure, acute renal failure, and major artery embolization occurred in 38 (27\%), $34(24 \%), 32(22.5 \%), 40(28 \%)$, and $90(63.4 \%)$ patients, respectively.

The NLR, total leucocyte count (TLC), neutrophil percentage, creatinine, and C-reactive protein (CRP) level obtained upon admission were significantly higher in the mortality group $[p \leq 0.001, p=0.008, p=0.001, p=0.004$, and $p=0.036$, respectively].

A higher NLR was significantly associated with fulminant sepsis and major arterial embolization $[p=0.001$ and $p=0.028$, respectively].

The receiver operating characteristic (ROC) curve of the NLR for predicting in-hospital mortality showed that an NLR $>8.085$ had a $60 \%$ sensitivity and an $84.8 \%$ specificity for an association with in-hospital mortality [area under the curve $=0.729,95 \%$ confidence interval $(\mathrm{Cl}) 0.616-0.841 ; p=0.001$ ]. The ROC curve of the NLR for predicting severe sepsis showed that an NLR $>5.035$ had a $71.8 \%$ sensitivity and a $68.5 \%$ specificity for predicting severe sepsis [area under the curve $0.685,95 \% \mathrm{Cl} 0.582-0.733 ; p=0.001$ ].

The PLR showed no significant association with in-hospital mortality or in-hospital complications.

Conclusion: A higher NLR, TLC, neutrophil percentage, creatinine level, and CRP level upon admission were associated with increased in-hospital mortality and morbidity in IE patients. Furthermore, a lower lymphocyte count/percentage and platelet count were strong indicators of in-hospital mortality among IE patients. Calculation of the NLR directly from a CBC upon admission may assist in early risk stratification of patients with IE.
\end{abstract}

Keywords: Infective endocarditis (IE), Neutrophil-to-lymphocyte ratio (NLR), Platelet-to-lymphocyte ratio (PLR)

\footnotetext{
* Correspondence: marwamashaal@kasralainy.edu.eg

${ }^{1}$ Cardiovascular Medicine Department, Kasr Al Ainy School of Medicine, Cairo

University, Cairo, Egypt

Full list of author information is available at the end of the article
} 


\section{Background}

Infective endocarditis (IE) is an infection of the heart valves (native or prosthetic); large intrathoracic vessels; intracardiac structures, such as the interventricular septum, chordae tendineae, or mural endocardium; and intracardiac foreign bodies. Despite improvements in the diagnosis and treatment of IE, the in-hospital mortality and morbidity rates of this infection remain high [1-4].

Recently, with the growing understanding of the roles of various inflammatory markers in IE, studies have focused on new, widely available, and inexpensive inflammatory markers. Recent studies have revealed that various markers, including the WBC count, neutrophilto-lymphocyte ratio (NLR), and mean platelet volume, are associated with IE and its prognosis [4-7].

The NLR, a novel marker, has been studied in various immunologic and infectious diseases as well as cardiologic disorders. The NLR is simply acquired using a complete blood count (CBC), which is the most commonly performed test in hospitals.

The NLR has been evaluated in various cardiac disorders, including atherosclerotic heart disease. Studies have revealed considerable prognostic value in addition to significant positive correlations. The predictive value of the NLR for peripheral arterial disease, calcific aortic stenosis, the presence, severity and extent of coronary artery disease, and many other cardiovascular disorders has been shown [8-15].

Platelets are well-established components of the hemostatic system. Recently, several additional functions of platelets have been demonstrated in the pathogenesis of various inflammatory diseases. The lymphocyte count is inversely correlated with inflammation. A lower lymphocyte count indicates an increased risk of inflammation, which correlates with cardiovascular disease burden and mortality $[15,16]$. Therefore, the platelet-tolymphocyte ratio (PLR) is positively correlated with inflammation and can therefore be a useful biomarker to predict the severity of inflammation.

Recently, the PLR was used as a worse prognostic marker for various cardiovascular conditions [17, 18]. However, very limited data are available regarding its predictive role in patients with IE [19]. In our study, we aimed to assess the relationship of the PLR and NLR that are obtained on admission with in-hospital morbidity and mortality in patients with IE, and we compared these two ratios.

\section{Methods}

\section{Study design}

This is a retrospective analytic study. Patients with definitive/possible IE according to the modified Duke criteria, as diagnosed by the Kasr Al Ainy IE Working Group from January 2011 through July 2016, were reviewed in this study. Only patients for whom full laboratory data were available were enrolled. The IE Working Group used the AHA/ACC guidelines and the ESC guidelines for the diagnosis and management of IE patients [1, 2].

At least three sets of blood cultures were collected for each patient prior to initiating antibiotics. Cultures were collected from different venepunctures, with the first and last samples drawn at least $1 \mathrm{~h}$ apart. Each blood culture set consisted of one BACTEC Plus Aerobic/F and one BACTEC Plus anaerobic/F culture vial (Becton Dickinson, Sparks, MD, UAE).

Surgically excised materials, including excised valves, vegetations, infected prostheses, aortic abscesses, and emboli, were submitted for Gram staining, potassium hydroxide preparation $(\mathrm{KOH})$, histopathological examination, and microbial culture.

Serodiagnosis for the detection of antibodies specific to Brucella, Bartonella, and Coxiella and Aspergillus Galactomannan Antigen was performed routinely for all patients.

Trans-thoracic echocardiography (TTE) was performed within $24 \mathrm{~h}$ of admission. Transesophageal echocardiography (TEE) was performed, as indicated, within $48-72 \mathrm{~h}$. All images were standardized according to the guidelines of the American Society of Echocardiography [20, 21].

All hematologic and biochemical data were obtained from venous blood samples drawn on the first day when patients were admitted to our hospital.

CBC hemoglobin, total leucocyte count (TLC), neutrophil, lymphocyte, and platelet counts were calculated using a Cell-Dyn 3700 automated cell counter. The PLR and NLR were directly obtained from the CBC on admission [22-24].

- Significant anemia was defined as a blood hemoglobin level $<10 \mathrm{mg} / \mathrm{dl}$ to avoid mild anemia that could be attributed to nutritional factors.

- Normal values of the TLC were defined as ranges from 4000 to $11000 / \mathrm{c} \mathrm{mm}$.

- Normal neutrophil percentage ranges were considered to be from 40 to $75 \%$.

- Normal lymphocyte percentage ranges were considered to be from 20 to $45 \%$.

- Normal platelet count ranges were considered to be from $150-400 \times 10^{3} / \mathrm{L}$.

C-reactive protein (CRP), serum creatinine, and rheumatoid factor levels were all assessed on admission and periodically across each patient's in-hospital course.

Severe (fulminant) sepsis was defined as sepsis necessitating ventilation or vasopressor support.

\section{Statistical analysis}

Data were coded and entered using the statistical package SPSS (Statistical Package for the Social Sciences) 
version 23. Data were summarized using the mean, standard deviation, median, minimum, and maximum for quantitative data and using frequencies (counts) and relative frequencies (percentages) for categorical data. Comparisons between quantitative variables were performed using the non-parametric Mann-Whitney test (Chan, 2003a) [25]. For comparing categorical data, the chi-square $\left(x^{2}\right)$ test was performed. An exact test was used instead when the expected frequency was less than 5 (Chan, 2003b) [26]. A receiver operating characteristic (ROC) curve was constructed, and an area under the curve analysis was performed to detect the best cutoff values of the PLR and NLR for detecting mortality and complications. Multivariate logistic regression was performed to identify independent predictors of mortality and complications. $p$ values less than 0.05 were considered as statistically significant [26].

\section{Approval}

The study protocol was approved by the Kasr Al Ainy Ethical Committee.

\section{Results}

We reviewed 217 patients who were admitted with a diagnosis of definitive/possible IE by the IE working group at Kasr Al Ainy Teaching Hospitals between January 2011 and July 2016. Complete hematological data were available for only 142 patients who were enrolled in the study.

Patients were young; the mean age was $30.95 \pm$ 11.03 years (ranges $12-71$ ). Males were more commonly affected than females (87 [61.3\%] versus 55 [38.7\%]). The median duration of hospitalization was 40 days (ranges 1-112 days).

\section{Predisposing risk factors}

Predisposing factors for IE were rheumatic heart disease (RHD) in 74 patients (52.1\%), prosthetic valve and intracardiac devices in 41 patients (28.9\%), intravenous (IV) drug abuse in 27 patients (19.1\%), congenital heart disease (CHD) in 12 patients (8.5\%), and degenerative heart disease in 3 patients (2.1\%). A history of previous IE was found in 8 patients (5.6\%).

\section{Causative organisms}

Causative organisms were identified by blood/tissue culture or serology in 85 patients $(59.9 \%)$. The most common organisms were Staphylococci [40 patients (47.1\%), $40 \%$ of them had methicillin-resistant $S$. aureus (MRSA)], followed by zoonotic organisms as a cause of IE in 14 patients (16.5\%) [Brucella spp. in 8 patients, Bartonella henselae in 5 patients and Coxiella burnetii in one patient], and Streptococci (12 patients, 14.1\%). Fungi were identified in 11 patients (12.9\%).

\section{Laboratory parameters}

CBCs were obtained on admission, and CBC parameters were analyzed. Serum creatinine, CRP, and rheumatoid factor levels were also analyzed. Patients were generally anemic with a mean hemoglobin level of $9.89 \pm 1.82 \mathrm{gm} /$ $\mathrm{dL}$ and a median of $9.75 \mathrm{gm} / \mathrm{dL}$ (range, $5.30-14.30 \mathrm{gm} /$ $\mathrm{dL}$ ). CRP levels were notably high, with a mean of $94.49 \pm 74.62 \mathrm{mg} / \mathrm{L}$. Serum creatinine levels were also elevated (mean, $2.19 \pm 6.56 \mathrm{mg} / \mathrm{dL}$ ).

Hematological and other laboratory characteristics on admission are shown in Table 1.

\section{Clinical course and in-hospital outcome}

Fifty-seven patients showed a good response to medical treatment, defined as improvement in the general condition of the patient, declining levels of inflammatory markers, and disappearance of fever in response to antimicrobial therapy without surgical intervention.

Cardiac surgery was indicated in 100 patients (70.4\%); however, it was only performed in 74 patients; some of the patients died short out of having surgery due to severe morbid condition while some others were scheduled for elective surgery after remission of acute IE episode. The most common indications for surgery were congestive heart failure (CHF) in 47 patients $(47 \%$ of the total patients with indications for surgery) followed by severe uncontrolled infection in 33 patients (33\%).

Major complications, including CHF (NYHA class IIIIV), cerebrovascular stroke (CVS), intracranial hemorrhage (ICH), acute renal failure (ARF) requiring dialysis, fulminant sepsis, and major arterial embolization, occurred in 107 patients of the whole group whether indicated for surgery or not. Table 2 shows the details of the complication incidences.

The overall in-hospital mortality was $21.1 \%$. The main causes of in-hospital death were fulminant sepsis, severe heart failure, and surgery-related mortality $(40 \%, 20 \%$, and $16.7 \%$ of overall mortality, respectively).

\section{Predictors of in-hospital mortality}

Fulminant sepsis, renal insufficiency (creatinine $>2 \mathrm{mg} /$ $\mathrm{dl}$ ), end-stage renal disease, splenic abscess/infarction, failure to respond to medical therapy alone, and major artery embolization were closely linked to mortality $(p<0.001, p<0.001, p=0.020, p=0.054, p<0.001$, and $p=0.065$, respectively). Clinical characteristics associated with increased in-hospital mortality are shown in Table 3.

Hemoglobin level was lower in the mortality group than in the non-mortality group (mean $9.31 \pm 1.87 \mathrm{~g} / \mathrm{dL}$ and $10.04 \pm 1.79 \mathrm{~g} / \mathrm{dL}, p=0.076$ ). A higher mean TLC on admission was noticed among the mortality group $(14.6 \pm 7.42 \times 103 / \mathrm{ml}$ and $10.84 \pm 4.66 \times 103 / \mathrm{ml}, \quad p=$ $0.008)$. The mean neutrophil percentage was significantly 
Table 1 Hematological and other laboratory characteristics of the patients

\begin{tabular}{|c|c|c|c|c|c|}
\hline Mean & Standard deviation & Median & & Minimum & Maximum \\
\hline ESR & 90.82 & 36.23 & 99.00 & 5.00 & 176.00 \\
\hline C-reactive protein (mg/L) & 94.49 & 74.62 & 84.00 & 9.00 & 597.00 \\
\hline Serum creatinine $(\mathrm{mg} / \mathrm{dL})$ & 2.19 & 6.56 & 1.00 & 0.39 & 12.00 \\
\hline Hemoglobin g/dL & 9.89 & 1.82 & 9.75 & 5.30 & 14.30 \\
\hline TLC & 11.63 & 5.55 & 10.70 & 3.70 & 35.60 \\
\hline Neutrophil percentage & 72.17 & 14.58 & 75.50 & 26.00 & 97.00 \\
\hline Lymphocyte percentage & 19.84 & 11.88 & 18.50 & 1.00 & 68.00 \\
\hline Lymphocyte count & 1951.83 & 974.27 & 1801.00 & 177.00 & 6300.00 \\
\hline Platelet count & 261.89 & 125.29 & 250.00 & 10.00 & 608.00 \\
\hline PLR & 159.22 & 108.82 & 128.01 & 9.34 & 902.91 \\
\hline NLR & 6.74 & 9.78 & 4.05 & .40 & 97.00 \\
\hline
\end{tabular}

ESR erythrocyte sedimentation rate, CHF congestive heart failure, NYHA New York Heart Association, ICH intracranial hemorrhage, SAH subarachnoid hemorrhage, $A R F$ acute renal failure

higher in the mortality group of patients $(78.87 \% \pm 15.11$ to $70.37 \% \pm 13.97$, respectively, $p=0.001$ ). A lower lymphocyte count/percentage and platelet count were strong indicators of the incidence of in-hospital mortality $(p=0.015, p<0.001$, and $p=0.001$, respectively). CRP levels on admission were significantly higher (as a continuous variable) in the mortality group (the mean CRP level was $110 \mathrm{mg} / \mathrm{L}$ in the mortality group vs. $91 \mathrm{mg} / \mathrm{L}$ in the survival group, $p=0.036$ ), and higher serum creatinine levels on admission and during hospitalization were significantly associated with an increased incidence of in-hospital mortality $(p=0.004$ and $p<0.001$, respectively).

A higher NLR was significantly associated with an increased incidence of in-hospital mortality $(p \leq 0.001)$, and the ROC curve of the NLR for predicting in-hospital

Table 2 Complication frequency in IE patients on admission and during hospitalization

\begin{tabular}{ll}
\hline & $\begin{array}{l}\text { Number of patients (\%) } \\
\text { (total N=142)* }\end{array}$ \\
\hline CHF class NYHA III-IV & $52(36.6 \%)$ \\
Systemic and pulmonary embolization & $90(63.4 \%)$ \\
Fulminant sepsis & $34(23.9 \%)$ \\
Stroke & $31(21.8 \%)$ \\
ICH/SAH & $11(7.7 \%)$ \\
Cerebral mycotic aneurysm & $9(6.3 \%)$ \\
ARF/renal insufficiency** & $40(28.2 \%)$ \\
Splenic abscess/infarction & $29(20.4 \%)$ \\
Acute limb ischemia & $4(2.8 \%)$ \\
Other complications & $3(2.1 \%)$ \\
\hline
\end{tabular}

CHF congestive heart failure, NYHA New York Heart Association, $\mathrm{ICH}$ intracranial hemorrhage, $S A H$ subarachnoid hemorrhage, ARF acute renal failure

* Most patients had more than one complication

**Renal insufficiency was defined as a serum creatinine level $>2 \mathrm{mg} / \mathrm{dl}$ mortality is shown in Fig. 1. An NLR over 8.085 measured upon admission had a $60 \%$ sensitivity and an $84.8 \%$ specificity for predicting in-hospital mortality [area under the curve $=0.729,95 \%$ confidence interval (CI) $0.616-0.841 ; p \leq 0.001]$.

Laboratory characteristics associated with increased in-hospital mortality are shown in Table 4.

The number of vegetations was significantly associated with mortality; the higher the number of vegetations was, the higher the risk of the in-hospital mortality $[p=0.002]$. Severe acute aortic regurgitation and prosthetic valve complications and MRSA or Candida infections were also associated with a high incidence of in-hospital mortality $[p=0.007, p=0.030$, and $p=$ 0.030 or $p=0.028$, respectively].

Through multivariate analysis, predictors of in-hospital mortality were a higher TLC on admission [odds ratio $(\mathrm{OR})=1.487 ; 95 \% \mathrm{CI}, 1.173$ to $1.863 ; p=0.001$ ], a low lymphocyte percentage on admission $[\mathrm{OR}=1.207$; $95 \%$

Table 3 Clinical and hematological predictors of in-hospital mortality in IE patients

\begin{tabular}{llll}
\hline & $\begin{array}{l}\text { Mortality } \\
(N=30)\end{array}$ & $\begin{array}{l}\text { Survival } \\
(N=112)\end{array}$ & $p$ value \\
\hline Heart failure on admission & $6(20 \%)$ & $10(8.9 \%)$ & 0.106 \\
Fulminant sepsis & $19(63.3)$ & $15(13.4 \%)$ & $<0.001$ \\
Renal insufficiency creatinine $>2 \mathrm{gm} / \mathrm{dl}$ & $17(56.7 \%)$ & $26(23.2 \%)$ & $<0.001$ \\
End stage renal disease & $12(40 \%)$ & $22(19.6)$ & 0.020 \\
Splenic abscess/infarction & $9(30 \%)$ & $20(17.9)$ & 0.054 \\
Lung abscess & $9(30)$ & $16(14.3 \%)$ & 0.103 \\
Cerebral hemorrhagic infarction & $4(13.3 \%)$ & $3(2.7 \%)$ & 0.036 \\
Intracranial/subarachnoid hemorrhage & $7(23.3 \%)$ & $4(3.6 \%)$ & 0.002 \\
Embolization to different organs & $23(76.6 \%)$ & $67(59.8 \%)$ & 0.065 \\
Responded to medical treatment & $3(10 \%)$ & $54(48.2 \%)$ & $<0.001$ \\
\hline
\end{tabular}




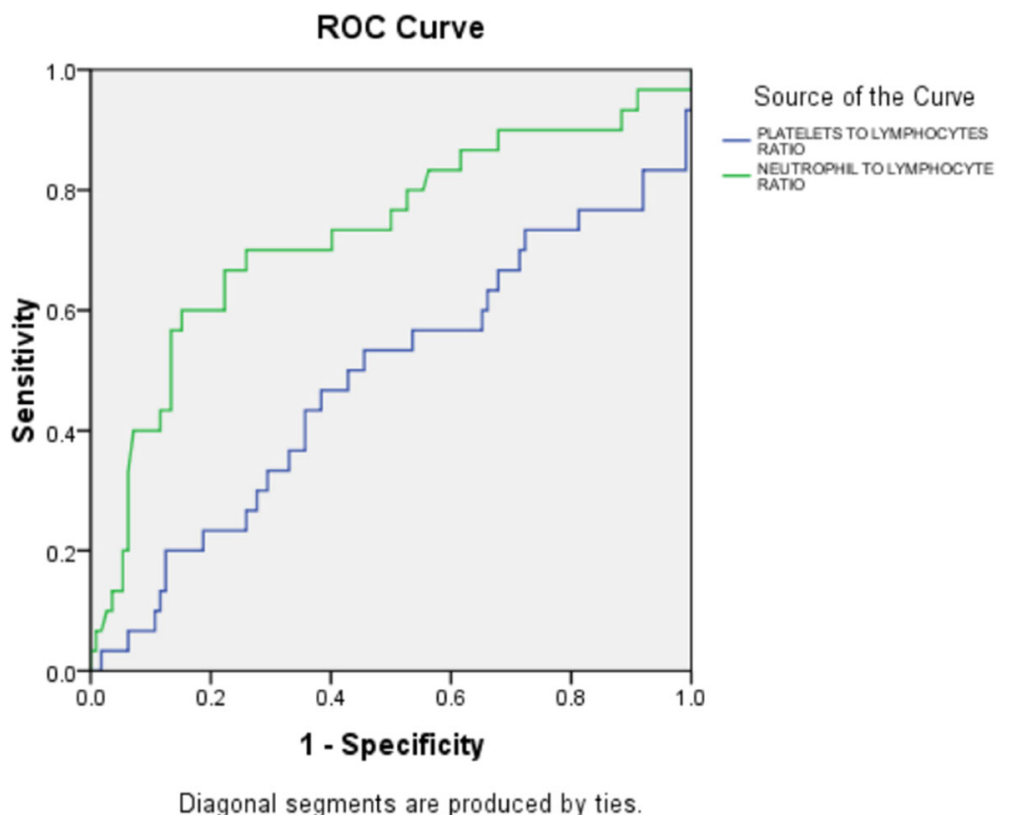

Fig. 1 ROC curve for predicting mortality using the platelet-to-lymphocyte ratio and neutrophil-to-lymphocyte ratio

CI, 1.015 to $1.435 ; p=0.033]$, and a low lymphocyte count on admission $[\mathrm{OR}=0.998$; $95 \% \mathrm{CI}, 0.996$ to 0.999 ; $p=0.008]$.

\section{Predictors of in-hospital morbidities}

A higher NLR was significantly associated with an increased incidence of fulminant sepsis and major artery embolization ( $p=0.001$ and $p=0.028$, respectively).

Table 4 Laboratory predictors of in-hospital mortality

\begin{tabular}{llll}
\hline & $\begin{array}{l}\text { Mortality } \\
(N=30)\end{array}$ & $\begin{array}{l}\text { Survival } \\
(N=112)\end{array}$ & $\begin{array}{l}P \\
\text { value }\end{array}$ \\
\hline $\begin{array}{l}\text { CRP on admission } \\
\begin{array}{l}\text { Creatinine on } \\
\text { admission }\end{array}\end{array}$ & $110(30-211)$ & $91(9-597)$ & 0.036 \\
$\begin{array}{l}\text { Highest creatinine } \\
\text { level }\end{array}$ & $3.99(0.7-12)$ & $2(0.2-15)$ & $<$ \\
$\begin{array}{l}\text { Hemoglobin on } \\
\text { admission }\end{array}$ & $9.13(5.3-12.7)$ & $10(5.9-14.3)$ & 0.004 \\
TLC on admission & $14.60(4-35.6)$ & $10.84(4.10-29)$ & 0.076 \\
$\begin{array}{l}\text { Neutrophil percentage } \\
\text { on admission }\end{array}$ & $78.87 \%(27-97 \%)$ & $70.37 \%(26-95 \%)$ & 0.008 \\
Lymphocyte & $14.2 \%(1-68 \%)$ & $21.35 \%(2-52 \%)$ & $<$ \\
percentage & & & 0.001 \\
Lymphocyte count & $1569.53(177-$ & $2054.2(270-$ & 0.015 \\
& $3672)$ & $6300)$ & \\
Platelet count & $202(10-587)$ & $277.9(56-608)$ & 0.001 \\
PLR & $150(9.24-395.5)$ & $161.7(26.9-9.2 .9)$ & 0.791 \\
NLR & $12.12(0.4-97)$ & $5.3(0.52-47.5)$ & $<$ \\
& & & 0.001 \\
\hline
\end{tabular}

The ROC curve of the NLR for predicting embolization to different organs is shown in Fig. 2. An NLR over 3.045 measured upon admission had a 73.3\% sensitivity and a $51.9 \%$ specificity for predicting embolization [area under the curve 0.611, 95\% CI 0.516-0.707; $p=0.028]$.

An NLR over 5.035 measured upon admission had a $71.8 \%$ sensitivity and a $68.5 \%$ specificity for predicting severe sepsis [area under the curve $0.685,95 \% \mathrm{CI}$ $0.582-0.733 ; p=0.001]$. The ROC curve of the NLR for predicting severe sepsis is shown in Fig. 3.

A higher CRP level on admission was also significantly associated with an increased incidence of CNS complications $(p=0.055)$.

While the PLR showed trends towards an increased incidence of in-hospital sepsis and major artery embolization ( $p=0.136$ and $p=0.186$, respectively), there was no association between a higher PLR and inhospital mortality in our patients.

\section{Discussion}

IE is an infrequent yet life-threatening disease with considerable morbidity and mortality rates that have been unchanged for more than 3 decades [1, 2, 6, 27]. The inhospital mortality rate of patients with IE varies from 15 to $30 \%$ [28-36].

Rapid identification of patients at highest risk of death may offer the opportunity to change the course of the disease (i.e., emergency or urgent surgery) and improve prognosis [37]. Current guidelines recommend additional protective measures in high-risk patients $[1,2]$; 


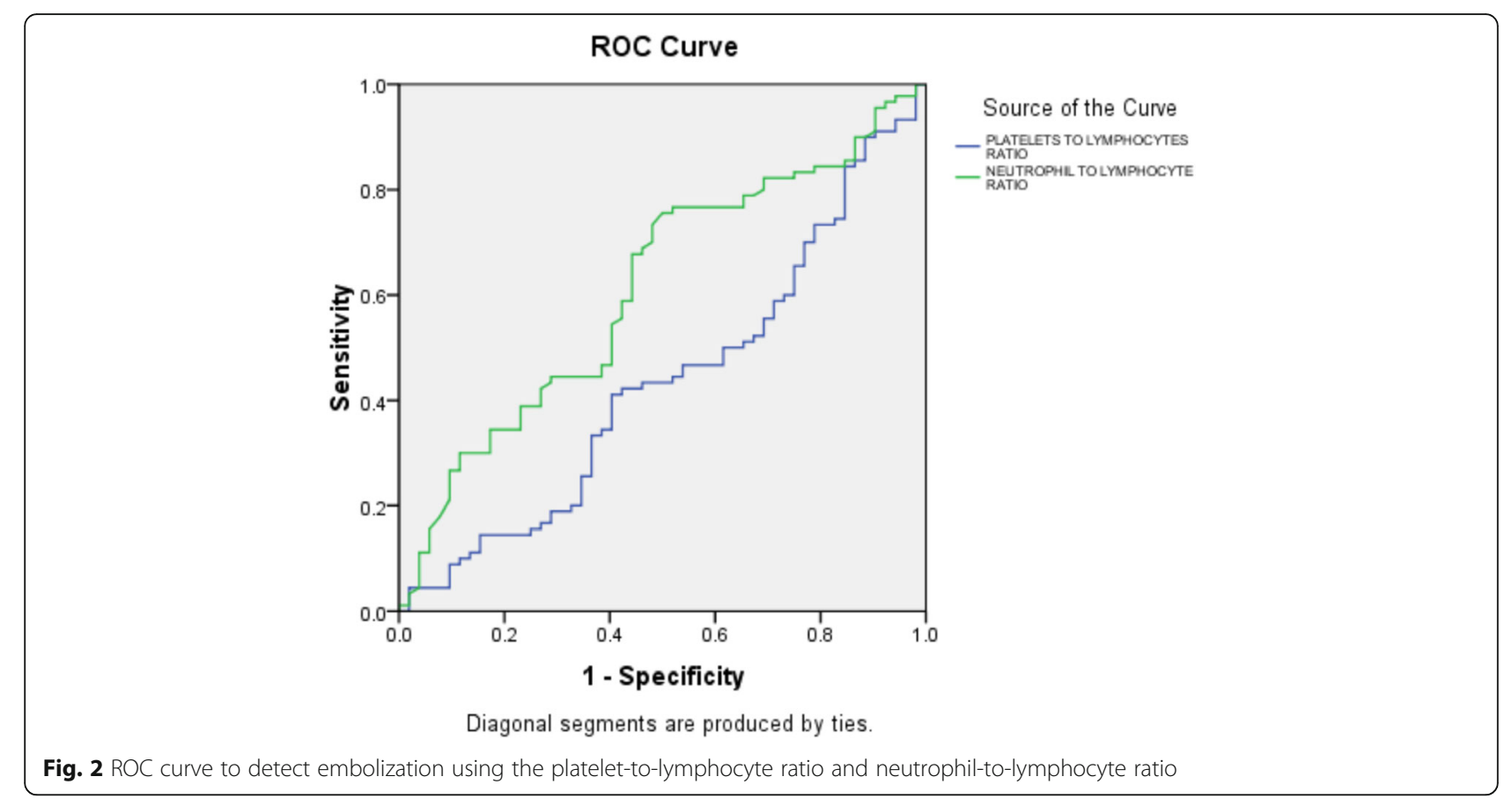

however, identifying patients at greater risk in the early phases of disease is not easy because of the non-uniformity and complexity of IE.

The PLR and NLR are independent predictors of worse prognosis in many infectious and cardiovascular diseases $[8-15,17,18]$; however, a very limited number of studies have been conducted to evaluate the prognostic role of these markers in IE $[5-7,19]$.
The aim of this study was to determine the value of the PLR and NLR as predictors of in-hospital morbidity and mortality among IE patients.

We analyzed clinical, laboratory, and echocardiographic data and the clinical course throughout the entire period of hospitalization in a total of 142 consecutive patients with definitive/possible IE diagnoses. The PLR and NLR were obtained directly from a CBC obtained upon admission.

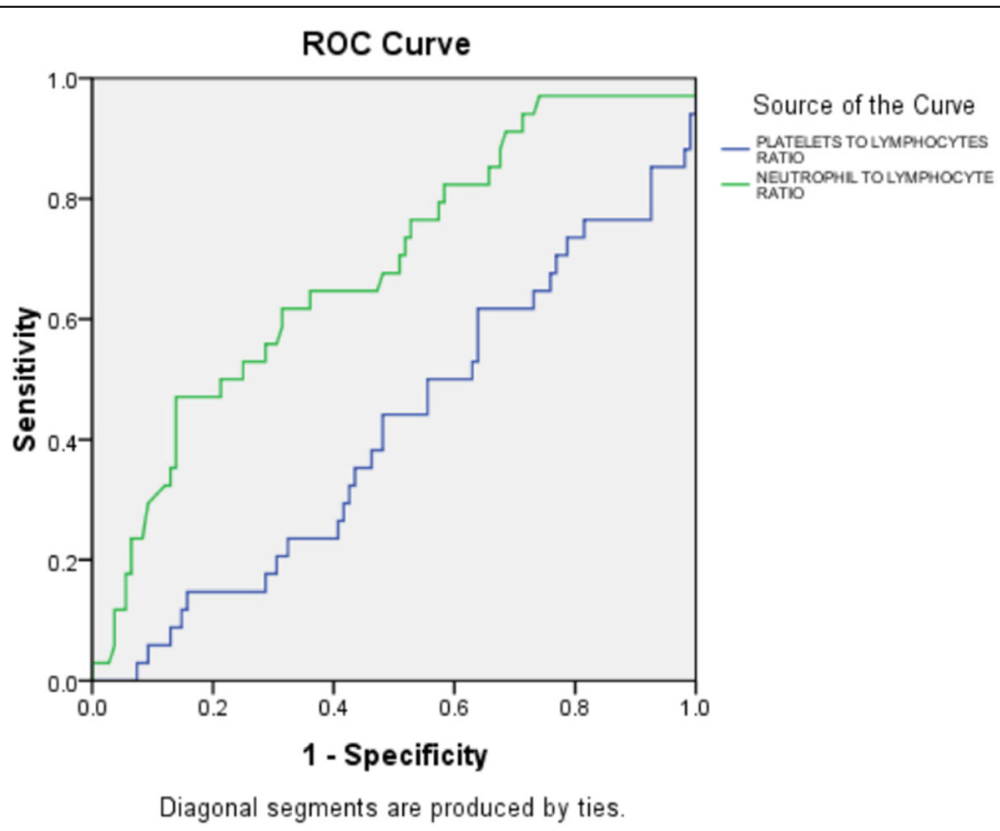

Fig. 3 ROC curve to detect severe sepsis using the platelet-to-lymphocyte ratio and neutrophil-to-lymphocyte ratio 
In our study, the mortality rate was $21 \%$ (30 patients), while complications of CVS, fulminant sepsis, acute heart failure, ARF, and embolization to different vital organs occurred in 38 (27\%), 34 (24\%), 32 (22.5\%), 40 (28\%), and 90 (63.4\%) patients, respectively.

We found that an NLR over 8.085 measured upon admission had a $60 \%$ sensitivity and an $84.8 \%$ specificity for predicting in-hospital mortality among IE patients [area under the curve $=0.729,95 \%$ CI $0.616-0.841 ; p \leq$ 0.001]; the high cutoff value in our study compared to the cutoff value of 7 from the study by Turak et al. [6] may be due to delayed presentation from the onset of disease symptoms (the mean time to referral in our study was 43 days) or introduction of antibiotics before referral, which alters the TLC and the NLR.

Additionally, we found that a high NLR on admission was significantly associated with an increased in-hospital incidence of severe sepsis. The ROC curve of the NLR for predicting severe sepsis shows that an NLR over 6.19 measured upon admission had a $71.8 \%$ sensitivity and a $68.5 \%$ specificity for predicting severe sepsis [area under the curve $=0.685,95 \%$ CI; 0.582-0.733, $p=0.001]$. This is also a higher cutoff value than that in the report by Turak et al. [6].

A higher NLR measured upon admission was also associated with an increased incidence of embolization to different organs $[p=0.028]$.

In our study, the PLR showed no significant association with in-hospital mortality or the occurrence of inhospital complications in IE patients. To the best of our knowledge, only one study has been conducted to evaluate the relationship between the PLR and in-hospital mortality in IE patients. Zencir et al. retrospectively analyzed the data from 59 patients diagnosed with definitive IE and found that a higher PLR on admission was associated with increased in-hospital mortality in patients with IE $(p=0.008)$ [19].

To date, very few reports have referred to a possible prognostic role of $\mathrm{CBC}$ parameters in identifying highrisk IE patients. Further studies might be needed to evaluate the prognostic significance of such parameters.

\section{Limitation of the study}

The study was limited by being a retrospective study and by being carried out in a tertiary referral center where patients were referred late, which might have increased the incidence of morbidities and mortality.

\section{Conclusion}

A CBC is an easy non-invasive test that is routinely performed on IE patients on admission and during followup. In our study, a higher NLR, TLC, and CRP and creatinine levels $(>1.99 \mathrm{mg} / \mathrm{dL})$ obtained upon admission were associated with increased in-hospital mortality and morbidity in IE patients. Additionally, a lower lymphocyte count/percentage and platelet count were strong indicators of in-hospital mortality among IE patients.

Calculation of the NLR directly from a CBC obtained upon admission may assist in early risk stratification of patients with IE.

\section{Abbreviations \\ ARF : Acute renal failure; CBC: Complete blood count; CHD: Congenital heart disease; CHF: Congestive heart failure; Cl: Confidence interval; CRP: C-reactive protein; CVS: Cerebrovascular stroke; ICH : Intracranial hemorrhage; IE: Infective endocarditis; $\mathrm{KOH}$ : Potassium hydroxide preparation; MRSA: Methicillin-resistant S. aureus; NLR: Neutrophil-to-lymphocyte ratio; PLR: Platelet-to-lymphocyte ratio; RHD : Rheumatic heart disease; ROC curve: Receiver operating characteristic curve; TEE: Transesophageal echocardiography; TLC: Total leucocyte count; TTE: Trans-thoracic echocardiography}

\section{Acknowledgements}

None

\section{Authors' contributions}

All authors contributed to the research equally. All authors read and approved the final manuscript.

\section{Funding}

The authors did not receive any specific funding.

\section{Availability of data and materials}

All data generated or analyzed during this study are included in this published article.

\section{Ethics approval and consent to participate}

The study was approved by the Kasr Al Ainy Ethical Committee. The ethical committee exempted the study from a specific consent, being a retrospective analytic study that reveals no identifiable personal or private information.

\section{Consent for publication}

Not applicable

\section{Competing interests}

The authors declare that they have no competing interests.

\section{Author details}

${ }^{1}$ Cardiovascular Medicine Department, Kasr Al Ainy School of Medicine, Cairo University, Cairo, Egypt. ${ }^{2}$ Clinical Pathology Department, Kasr Al Ainy School of Medicine, Cairo University, Cairo, Egypt.

Received: 30 June 2019 Accepted: 24 July 2019

Published online: 18 September 2019

\section{References}

1. Habib G, Lancellotti P, Antunes MJ, Bongiorni MG, Casalta JP, Del Zotti F et al (2015) 2015 ESC guidelines for the management of infective endocarditis: the task force for the management of infective endocarditis of the European Society of Cardiology (ESC) endorsed by: European Association for CardioThoracic Surgery (EACTS), the European Association of Nuclear Medicine (EANM). Eur Heart J 36(44):3075-3128

2. Baddour LM, Wilson WR, Bayer AS, Fowler VG Jr, Bolger AF, Levison ME et al (2005) Infective endocarditis: diagnosis, antimicrobial therapy, and management of complications: a statement for healthcare professionals from the Committee on Rheumatic Fever, Endocarditis, and Kawasaki Disease, Council on Cardiovascular Disease in the Young, and the Councils on Clinical Cardiology, Stroke, and Cardiovascular Surgery and Anesthesia, American Heart Association: endorsed by the Infectious Diseases Society of America. Circulation. 111(23):e394-e434

3. Moreillon P, Que YA (2004) Infective endocarditis. Lancet. 363(9403):139-149

4. Gunebakmaz O, Kaya MG, Kaya EG, Ardic I, Yarlioglues M, Dogdu O et al (2010) Mean platelet volume predicts embolic complications and prognosis in infective endocarditis. Int J Infect Dis 14(11):e982-e985 
5. Cornelissen CG, Frechen DA, Schreiner K, Marx N, Krüger S (2013) Inflammatory parameters and prediction of prognosis in infective endocarditis. BMC Infect Dis 13(1):272

6. Turak O, Özcan F, Işleyen A, Başar FN, Gül M, Yilmaz S et al (2013) Usefulness of neutrophil-to-lymphocyte ratio to predict in-hospital outcomes in infective endocarditis. Can J Cardiol 29(12):1672-1678

7. Bozbay M, Ugur M, Uyarel H, Cicek G, Koroglu B, Tusun E et al (2014) Neutrophil-to-lymphocyte ratio as a prognostic marker in infective endocarditis: in-hospital and long-term clinical results. J Heart Valve Dis 23(5):617-623

8. González-Fajardo JA, Brizuela-Sanz JA, Aguirre-Gervás B, Merino-Díaz B, Del Río-Solá L, Martín-Pedrosa M et al (2014) Prognostic significance of an elevated neutrophil-lymphocyte ratio in the amputation-free survival of patients with chronic critical limb ischemia. Ann Vasc Surg 28(4):999-1004

9. Açar G, Fidan S, Uslu ZA, Turkday S, Avci A, Alizade E et al (2015) Relationship of neutrophil-lymphocyte ratio with the presence, severity, and extent of coronary atherosclerosis detected by coronary computed tomography angiography. Angiology. 66(2):174-179

10. Arbel Y, Finkelstein A, Halkin A, Birati EY, Revivo M, Zuzut M et al (2012) Neutrophil/lymphocyte ratio is related to the severity of coronary artery disease and clinical outcome in patients undergoing angiography. Atherosclerosis. 225(2):456-460

11. Avci A, Elnur A, Göksel A, Serdar F, Servet I, Atilla K et al (2014) The relationship between neutrophil/lymphocyte ratio and calcific aortic stenosis. Echocardiography. 31(9):1031-1035

12. Shah N, Parikh V, Patel N, Patel N, Badheka A, Deshmukh A et al (2014) Neutrophil lymphocyte ratio significantly improves the Framingham risk score in prediction of coronary heart disease mortality: insights from the National Health and Nutrition Examination Survey-III. Int J Cardiol 171(3): 390-397

13. Ommen OS, Gibbons GR, Hodge HD, Thomson TS (1997) Usefulness of the lymphocyte concentration as a prognostic marker in coronary artery disease. Am J Cardiol 79(6):812

14. Horne BD, Anderson JL, John JM, Weaver A, Bair TL, Jensen KR et al (2005) Which white blood cell subtypes predict increased cardiovascular risk? J Am Coll Cardiol 45(10):1638-1643

15. Sandhaus LM, Meyer $P$ (2002) How useful are CBC and reticulocyte reports to clinicians? Am J Clin Pathol 118(5):787-793

16. Bath PM, Butterworth RJ (1996) Platelet size: measurement, physiology and vascular disease. Blood Coagul Fibrinolysis 7(2):157-161

17. Ayça B, Akin F, Çelik Ö, Yüksel Y, Öztürk D, Tekiner F, Çetin Ş, Okuyan E, Dinçkal MH (2015) Platelet to lymphocyte ratio as a prognostic marker in primary percutaneous coronary intervention. Platelets. 26(7):638-644

18. Hudzik B, Szkodzinski J, Gorol J, Niedziela J, Lekston A, Gasior M et al (2015) Platelet-to-lymphocyte ratio is a marker of poor prognosis in patients with diabetes mellitus and ST-elevation myocardial infarction. Biomarkers Med 9(3):199-207

19. Zencir C, Akpek M, Senol S, Selvi M, Onay S, Cetin M et al (2015) Association between hematologic parameters and in-hospital mortality in patients with infective endocarditis. Kaohsiung J Med Sci 31(12):632-638

20. Cheitlin MD, Armstrong WF, Aurigemma GP, Beller GA, Bierman FZ, Davis JL et al (2003) ACC/AHA/ASE 2003 guideline update for the clinical application of echocardiography: summary article: a report of the American College of Cardiology/American Heart Association Task Force on Practice Guidelines (ACC/AHA/ASE Committee to Update the 1997 Guidelines for the Clinical Application of Echocardiography). J Am Coll Cardiol 42(5):954-970

21. Habib G, Badano L, Tribouilloy C, Vilacosta I, Zamorano JL, Galderisi M (2010) Recommendations for the practice of echocardiography in infective endocarditis. Eur J Echocardiogr 11(2):202-219

22. Tefferi A, Hanson CA, Inwards DJ. How to interpret and pursue an abnormal complete blood cell count in adults. In Mayo Clinic Proceedings 2005(Vol. 80, No. 7, pp. 923-936). Elsevier.

23. Fairbanks VF, Tefferi A (2000) Normal ranges for packed cell volume and hemoglobin concentration in adults: relevance to 'apparent polycythemia'. Eur J Haematol. 65(5):285-296

24. Shearer WT, Rosenblatt HM, Gelman RS, Oyomopito R, Plaeger S, Stiehm ER et al (2003) Lymphocyte subsets in healthy children from birth through 18 years of age: the Pediatric AIDS Clinical Trials Group P1009 study. J Allergy Clin Immunol 112(5):973-980

25. Chan YH (2003) Biostatistics 102: quantitative data-parametric \& non-parametric tests. Blood Press 140(24.08):79-00
26. Chan YH (2003) Biostatistics 103: qualitative data-tests of independence. Singapore Med J. 44(10):498-503

27. Tornos P, Gonzalez-Alujas T, Thuny F, Habib G (2011) Infective endocarditis: the European viewpoint. Curr Probl Cardiol 36(5):175-222

28. Duval X, Delahaye F, Alla F, Tattevin P, Obadia JF, Le Moing V et al (2012) Temporal trends in infective endocarditis in the context of prophylaxis guideline modifications: three successive population-based surveys. J Am Coll Cardiol 59(22):1968-1976

29. Murdoch DR, Corey GR, Hoen B, Miró JM, Fowler VG, Bayer AS et al (2009) Clinical presentation, etiology, and outcome of infective endocarditis in the 21st century: the International Collaboration on Endocarditis-Prospective Cohort Study. Arch Intern Med 169(5):463-473

30. Nadji G, Rusinaru D, Rémadi JP, Jeu A, Sorel C, Tribouilloy C (2009) Heart failure in left-sided native valve infective endocarditis: characteristics, prognosis, and results of surgical treatment. Eur J Heart Fail 11(7):668-675

31. Thuny F, Disalvo G, Belliard O, Avierinos JF, Pergola V, Rosenberg V et al (2005) Risk of embolism and death in infective endocarditis: prognostic value of echocardiography: a prospective multicenter study. Circulation. 112(1):69-75

32. Leone S, Ravasio V, Durante-Mangoni E, Crapis M, Carosi G, Scotton PG et al (2012) Epidemiology, characteristics, and outcome of infective endocarditis in Italy: the Italian Study on Endocarditis. Infection. 40(5):527-535

33. Meshaal MS, Labib D, Said K, Hosny M, Hassan M, Al Aziz SA et al (2018) Aspergillus endocarditis: diagnostic criteria and predictors of outcome. A retrospective cohort study. PloS One. 13(8):e0201459

34. Meshaal MS, Kassem HH, Samir A, Zakaria A, Baghdady Y, Rizk HH (2015) Impact of routine cerebral CT angiography on treatment decisions in infective endocarditis. PloS One. 10(3):e0118616

35. García-Cabrera E, Fernández-Hidalgo N, Almirante B, Ivanova-Georgieva R, Noureddine M, Plata A et al (2013) Neurological complications of infective endocarditis: risk factors, outcome, and impact of cardiac surgery: a multicenter observational study. Circulation. 127(23):2272-2284

36. Delahaye F, Alla F, Béguinot I, Bruneval P, Doco-Lecompte T, Lacassin $F$ et al (2007) AEPEI GROUP. In-hospital mortality of infective endocarditis: prognostic factors and evolution over an 8-year period. Scand J Infect Dis 39(10):849-857

37. Olmos C, Vilacosta I, Fernandez C, Lopez J, Sarria C, Ferrera C et al (2012) Contemporary epidemiology and prognosis of septic shock in infective endocarditis. Eur Heart J 34(26):1999-2006

\section{Publisher's Note}

Springer Nature remains neutral with regard to jurisdictional claims in published maps and institutional affiliations.

\section{Submit your manuscript to a SpringerOpen ${ }^{\circ}$ journal and benefit from:}

- Convenient online submission

- Rigorous peer review

- Open access: articles freely available online

- High visibility within the field

- Retaining the copyright to your article

Submit your next manuscript at $\boldsymbol{\nabla}$ springeropen.com 